\title{
The significance of Notch ligand expression in the peripheral blood of children with hand, foot and mouth disease (HFMD)
}

Zhen Jiang Bai ${ }^{1 \dagger}$, Yi Ping $\mathrm{Li}^{2 \dagger}$, Jie Huang ${ }^{2}$, Yong Jun Xiang ${ }^{3}$, Chun Yu Lu ${ }^{3}$, Xiao Xing Kong ${ }^{4}$, Jian Mei Tian ${ }^{4}$, Jiang Huai Wang ${ }^{5}$ and Jian Wang ${ }^{3 *}$

\begin{abstract}
Background: Hand, foot and mouth disease (HFMD), a virus-induced infectious disease that usually affects infants and children, has an increased incidence in China in recent years. This study attempted to investigate the role of the Notch signaling pathway in the pathogenesis of HFMD.

Methods: Eighty-two children diagnosed with HFMD were enrolled into this study. The HFMD group was further divided into the uncomplicated HFMD and HFMD with encephalitis groups. The control group included 40 children who underwent elective surgery for treatment of inguinal hernias.

Results: Children with HFMD displayed significantly reduced $\mathrm{CD}^{+}, \mathrm{CD}^{+} \mathrm{CD}^{+}$and $\mathrm{CD}^{+} \mathrm{CD}^{+}$cell subsets, but substantially enhanced $\mathrm{CD}^{-} \mathrm{CD} 19^{+}$cell subset ( $p<0.05$ versus control subjects). The expression levels of Notch ligands DII1 and DII4 in the peripheral blood of the HFMD group were significantly higher than those in the control group $(p<0.05)$. There were statistically significant differences in $\mathrm{CD}^{+}, \mathrm{CD}^{+} \mathrm{CD}^{+}$and $\mathrm{CD}^{-} \mathrm{CD} 19^{+}$cell subsets, but not in Notch ligand expression, between the uncomplicated HFMD and HFMD with encephalitis groups. DII4 expression in HFMD subjects correlated negatively with the $\mathrm{CD}^{+}$and $\mathrm{CD}^{+}{ }^{+} \mathrm{CD} 8^{+}$cell subsets $(p<0.05)$, but positively with the $\mathrm{CD}^{-} \mathrm{CD}_{19}{ }^{+}$cell subset $(p<0.05)$. Furthermore, Dll4 expression in HFMD with encephalitis subjects correlated positively with total white blood cell (WBC) counts and total protein contents in cerebrospinal fluid (CSF) $(p<0.05)$.

Conclusions: The Notch ligand DII4 exhibits a strong correlation with the $\mathrm{CD}^{+}, \mathrm{CD}^{+} \mathrm{CD}^{+}$and $\mathrm{CD} 3^{-} \mathrm{CD} 19^{+}$cell subsets in children with HFMD, indicating that the Notch signaling may be involved in the development of HFMD by affecting the number and status of peripheral lymphocytes.
\end{abstract}

Keywords: Notch signaling, Subsets of T lymphocytes, Hand, Foot and mouth disease, Children

\section{Background}

Hand, foot and mouth disease (HFMD) is a common infectious disease worldwide, which usually affects infants and children. In recent years, HFMD has become increasingly prevalent in the Asia-pacific region, particularly in China. HFMD is contagious and can be lethal in infants and children with severe cases. In China, there were 1,619,706 HFMD cases diagnosed with 509 deaths in 2011, 2,168,737 HFMD cases diagnosed with 567 deaths in 2012, and

\footnotetext{
*Correspondence: wj196312@vip.163.com

${ }^{\dagger}$ Equal contributors

${ }^{3}$ Department of Pediatric Surgery, Affiliated Children's Hospital, Soochow University, Suzhou, China

Full list of author information is available at the end of the article
}

1,828,377 HFMD cases diagnosed with 252 deaths in 2013, respectively [1,2]. The major pathogens of HFMD in these cases were enterovirus 71 (EV71) and coxsackie A virus A16 (CoxA 16) [1,2], but the precise mechanism (s) for the pathogenesis of HFMD has not yet been fully elucidated. Previous studies reported that children with HFMD displayed substantial immune disorders [3,4].

Notch signaling can promote or suppress cell proliferation, cell death, acquisition of specific cell fates, or activation of differentiation programs in a context-dependent manner, thus controlling cell fate and tissue homeostasis [5]. It has been shown that the Notch signaling pathway links both the innate immunity and the adaptive immunity,

\section{Biomed Central}


and affects the differentiation and development of $\mathrm{T}$ cells, $B$ cells and natural killer (NK) cells, thereby playing an important role in the activation of host immune system against infectious disease [6-8]. Furthermore, Notch ligands Dll1 and Dll4 are both involved in the initiation of an anti-viral response $[9,10]$. While type-I IFN-induced Dll1 expression on macrophages plays a critical role in preventing influenza A virus infection [9], Dll4 appears to limit physiologic and pathologic changes in the lung during respiratory syncytial virus infection by modulating the Th2 response [10]. However, it is unclear whether the Notch signaling is involved in the pathogenesis of HFMD. To our knowledge, there has been no previous work reported on the role of the Notch signaling pathway in HFMD. In the present study, we attempted to identify correlations between the Notch signaling pathway and the immune status in pediatric patients with HFMD by assessing expression levels of Notch ligands and subsets of lymphocytes in the peripheral blood collected from children with HFMD. Our findings suggest a possible role for the Notch signaling pathway in HFMD.

\section{Methods}

\section{Study population}

A total of 82 pediatric patients who were admitted into the infection ward and Pediatric Intensive Care Unit of Affiliated Children's Hospital, Soochow University, Suzhou, China and diagnosed with HFMD between June 2012 and December 2012 were recruited into this study. Among 82 cases, 42 cases with no complications were included in the uncomplicated HFMD group and 40 cases with encephalitis were included in the HFMD with encephalitis group. There were 26 males and 16 females in the uncomplicated group with an average age of 2.23 years ranging from 0.33 to 7 years and 24 males and 16 females in the encephalitis group with an average age of 2.6 years ranging from 0.75 to 9 years. The control group was comprised of 40 children ( 35 males and 5 females) with average age of 5.33 years ranging from 0.25 to 14 years who were scheduled for elective surgery of inguinal hernia repair. This study was approved by the Institutional Research Ethics Committee of Affiliated Children's Hospital and Soochow University for clinical investigation, and the written informed consent was obtained from all study participants and/or their parents or guardians before enrollment. All experiments and procedures followed were conducted in accordance with the principles of the Declaration of Helsinki involving human subjects.

The diagnosis of HFMD and HFMD with encephalitis was based on the WHO diagnostic criteria [11]. Symptoms in HFMD children include fever and rashes (maculopapule, papules and small herpes) located on the hands, feet, mouth and buttocks, potentially accompanied by coughing, runny nose and lack of appetite. HFMD children complicated with encephalitis could display meningitis, encephalitis, poliomyelitis-like syndrome and encephalomyelitis symptoms and signs including weakness, lethargy, hyperarousal, headache, vomiting, dysphoria, shaky limbs, acute limb weakness and stiff neck, etc. Analysis of cerebrospinal fluid (CSF) in children with HFMD subjects revealed aseptic meningitis changes. Pediatric Risk of Mortality III (PRISM III) [12] was used to assess the disease severity in children with HFMD.

\section{Real-time qPCR}

Real-time quantitative RT-PCR (q-PCR) was used to detect the expression levels of Notch ligands Dll1, Dll4, Jagged1 and Jagged2 in the peripheral blood. Total RNA was extracted using TRIzol (Invitrogen) and the singlestranded cDNA was synthesized using M-MLV reverse transcriptase (Invitrogen). Real-time qPCR was performed with the SYBR Green PCR Mix on a LightCycler System (Roche). The primers sequences used were hJAG1 sense5'AATGGTTATCGCTGTATCTG-3' and antisense-5'-TC ACTGGCACGGTTGTAG-3', hJAG2 sense-5'-AGTTCCA GTGCGATGCCTACA-3' and antisense-5'-GCTACAGCG ATACCCGTTGAT-3', hDLL1 sense-5'-GGGTCATCCTT GTCCTCAT-3' and antisense-5'-CTTGGTGTCACGCTT GCT-3', hDLL4 sense-5'-ACAGCCTATCTGTCTTTCGG-3' and antisense-5'-GGCAGTGGTAGCCATCCT-3' and glyceraldehyde 3-phosphate dehydrogenase (GAPDH), sense5'-AAGCTCACTGGCATGGCCTT-3' and antisense-5'CTCTCTTCCTCTTGTGCTCTT G-3'. The transcript abundance was calculated using the $\Delta \Delta C$ t method, and the mRNA expression level of each Notch ligand was the ratio of normalized mean of GAPDH.

\section{FACScan analysis}

Heparinized blood samples collected from different groups were dual- or triple-stained with anti-human CD3 (clone UCHT1, Beckman Coulter, Fullerton, CA), anti-human CD4 (clone SFCI12T4D11, Beckman Coulter), anti-human CD8 (clone SFCI21Thy2D3, Beckman Coulter), anti-human CD16 (clone 3G8, Beckman Coulter), anti-human CD19 (clone 89B, Beckman Coulter) and anti-human CD56 (clone N901, Beckman Coulter) mAbs conjugated with phycoerythrin (PE), fluorescein isothiocyanate (FITC) or phycoerythrin-Texas Red (ECD). PE-, FITC- or ECDconjugated anti-human isotype-matched mAbs (Beckman Coulter) were used as negative controls. Erythrocytes were lysed with OptiLyse C (Beckman Coulter). FACScan analysis was performed for at least 10,000 events for detection of lymphocyte subsets in the peripheral blood including $\mathrm{CD}^{+}, \mathrm{CD}^{+} \mathrm{CD}^{+}, \mathrm{CD}^{+} \mathrm{CD}^{+}, \mathrm{CD}^{-} \mathrm{CD} 19^{+}$ and $\mathrm{CD}^{-} \mathrm{CD} 16^{+} \mathrm{CD} 56^{+}$cells on a Coulter FC500 flow cytometer (Beckman Coulter) equipped with EXPO32 software (Beckman Coulter). 
Total WBC counting and protein measurement in CSF CSF samples were collected from subjects in HFMD with encephalitis group. A $100 \mu \mathrm{l}$ CSF sample was used to determine total WBC counts using a haemacytometer. Total protein contents in CSF samples were assessed by micro pyrogallol red colorimetric method.

\section{Statistical analysis}

Results are expressed as mean \pm standard deviation (SD). Data were collected and analyzed using GraphPad software, version 5.01 (Prism, La Jolla, CA). All data were tested for normal distribution and homogeneity of variance. The unpaired student's t-test was used to compare the means between two groups. The unpaired student's t-test with Welch's correction was used to analyze nonnormally distributed values. The Spearman rank correlation coefficient test was used to assess correlations between Notch ligand expression and lymphocyte subsets in the peripheral blood. A $p$-value of less than 0.05 was considered to be statistically significant.

\section{Results}

Alterations in peripheral lymphocyte subsets in HFMD subjects

The numbers of $\mathrm{CD}^{+}(p=0.014), \mathrm{CD}^{+} \mathrm{CD}^{+}(p=0.006)$ and $\mathrm{CD}^{+} \mathrm{CD}^{+}(p=0.001)$ cells in the peripheral blood of the HFMD group were significantly lower than those in the control group, whereas the number of $\mathrm{CD}^{-} \mathrm{CD} 19^{+}$ cells $(p=0.007)$ in the peripheral blood of the HFMD group was significantly higher than that in the control group (Table 1). No significant difference in the number of peripheral $\mathrm{CD}^{-} \mathrm{CD} 16^{+} \mathrm{CD} 56^{+}$cells was found between the HFMD and control groups (Table 1). The numbers of peripheral $\mathrm{CD}^{+}(p=0.023)$ and $\mathrm{CD}^{+}{ }^{+} \mathrm{CD} 4^{+}(p=0.039)$ cells in the uncomplicated HFMD group were substantially higher than those in the HFMD with encephalitis group, whereas the number of peripheral $\mathrm{CD}^{-} \mathrm{CD} 19^{+}$ cells $(p=0.001)$ was significantly lower in the uncomplicated HFMD group compared to the HFMD with encephalitis group (Table 2). There were no significant differences in the numbers of peripheral $\mathrm{CD}^{+} \mathrm{CD}^{+}$

Table 1 Comparison of lymphocyte subsets in the peripheral blood between the control group $(n=40)$ and the HFMD group $(n=82)$

\begin{tabular}{lccc}
\hline Lymphocyte subsets (\%) & Control & HFMD & $\boldsymbol{p}$ values \\
\hline $\mathrm{CD3}^{+}$ & $59.94 \pm 6.41$ & $56.52 \pm 9.83$ & 0.014 \\
$\mathrm{CD}^{+}{ }^{+} \mathrm{CD} 4^{+}$ & $32.15 \pm 6.31$ & $28.57 \pm 8.36$ & 0.006 \\
$\mathrm{CD}^{+} \mathrm{CD} 8+$ & $26.42 \pm 5.65$ & $22.70 \pm 6.59$ & 0.001 \\
$\mathrm{CD}^{-} \mathrm{CD} 19^{+}$ & $21.41 \pm 6.38$ & $24.93 \pm 8.50$ & 0.007 \\
$\mathrm{CD3}^{-} \mathrm{CD} 16^{+} \mathrm{CD}^{+} 6^{+}$ & $17.08 \pm 5.99$ & $15.82 \pm 8.10$ & 0.306 \\
\hline
\end{tabular}

Data are mean \pm SD. Statistical significance was evaluated by unpaired student's t-test.
Table 2 Comparison of lymphocyte subsets in the peripheral blood between the uncomplicated HFMD group $(n=42)$ and the HFMD with encephalitis group ( $n=40$ )

\begin{tabular}{lccc}
\hline Lymphocyte subsets (\%) & Uncomplicated & Encephalitis & $\boldsymbol{p}$ values \\
\hline $\mathrm{CD}^{+}$ & $58.42 \pm 8.99$ & $54.21 \pm 10.40$ & 0.023 \\
$\mathrm{CD}^{+} \mathrm{CD} 4^{+}$ & $30.04 \pm 8.87$ & $26.79 \pm 7.40$ & 0.039 \\
$\mathrm{CD}^{+} \mathrm{CD} 8+$ & $23.14 \pm 6.42$ & $22.00 \pm 6.88$ & 0.443 \\
$\mathrm{CD}^{-} \mathrm{CD} 19^{+}$ & $22.62 \pm 7.87$ & $27.74 \pm 8.46$ & 0.001 \\
$\mathrm{CD}^{-} \mathrm{CD} 16^{+} \mathrm{CD} 56^{+}$ & $16.40 \pm 7.38$ & $15.13 \pm 8.92$ & 0.412
\end{tabular}

Data are mean $\pm S D$. Statistical significance was evaluated by unpaired student's t-test.

and $\mathrm{CD}^{-} \mathrm{CD} 16^{+} \mathrm{CD} 56^{+}$cells found between the uncomplicated HFMD and HFMD with encephalitis groups (Table 2).

Levels of Notch ligand expression between HFMD and control subjects

The expression levels of Notch ligands Dll1 $(p=0.000)$ and Dll4 $(p=0.002)$ in the peripheral blood of the HFMD group were significantly higher than those of the control group (Figure 1); however, there were no significant differences in Jagged1 and Jagged2 expression levels found between the HFMD and control groups (Figure 1). There were also no significant differences in Dll1, Dll4, Jagged1 and Jagged2 expression levels found between the uncomplicated HFMD and HFMD with encephalitis groups (Figure 2).

\section{Correlations between DII4 expression and peripheral lymphocyte subsets}

The expression levels of Notch ligand Dll4 in the peripheral blood of the HFMD group correlated negatively with the numbers of peripheral CD3 ${ }^{+}(\mathrm{R}$-square $=-0.299, p=0.004)$ and $\mathrm{CD}^{+} \mathrm{CD}^{+}(\mathrm{R}$-square $=-0.234, p=0.025)$ lymphocytes, but correlated positively with the number of peripheral $\mathrm{CD}^{-} \mathrm{CD}^{-} 9^{+}$lymphocyte (R-square $=0.364, p=0.000$ ) (Figure 3). There were no correlations found between Dll4 levels and peripheral $\mathrm{CD}^{+} \mathrm{CD}^{+}$(R-square $=-0.098$, $p=0.351)$ and $\mathrm{CD}^{-} \mathrm{CD}^{+} 6^{+} \mathrm{CD}^{+} 6^{+}$(R-square $=0.020, p=$ 0.853 ) cell counts (Figure 3 ). By contrast, the expression levels of Dll1 did not correlated with the numbers of peripheral lymphocyte subsets (data not shown).

\section{Association between DII4 expression levels and HFMD}

A positive correlation was found in the HFMD with encephalitis group between Dll4 expression levels in the peripheral blood and total WBC counts in CSF (R-square = $0.445, p=0.005$ ) as well as between Dll4 expression levels in the peripheral blood and total protein contents in CSF ( $\mathrm{R}$-square $=0.372, p=0.012$ ) (Figure 4). However, the expression levels of Dll4 in the peripheral blood of HFMD subjects did not correlate significantly 

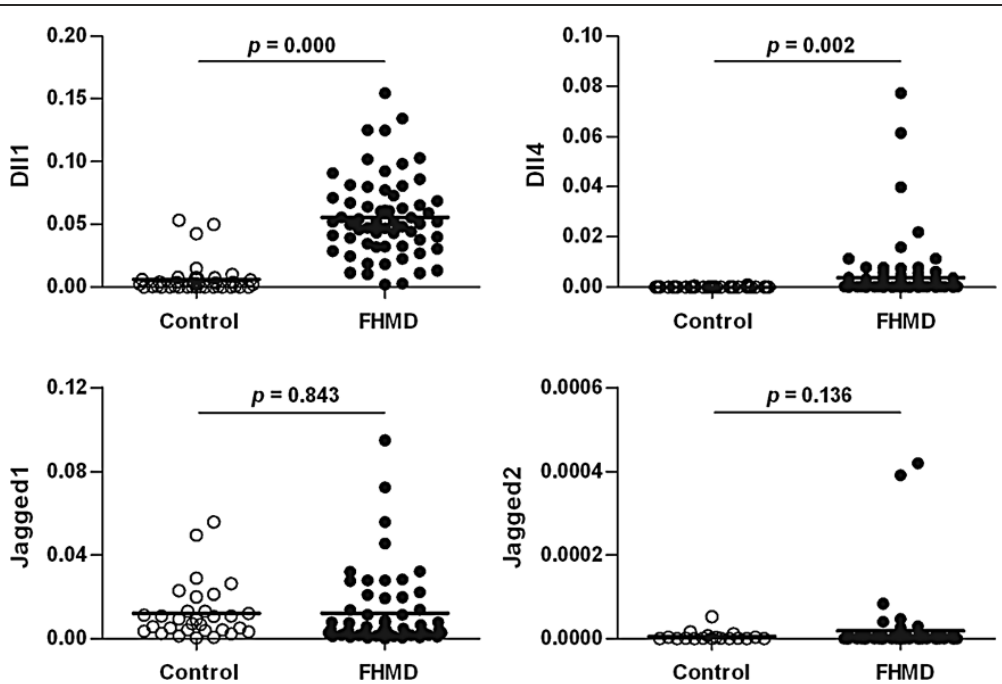

Figure 1 Comparison of the expression levels of Notch ligands DII1, DII4, Jagged1 and Jagged2 in the peripheral blood between the control group $(\mathbf{n}=\mathbf{4 0})$ and the HFMD group $(\mathbf{n}=\mathbf{8 2})$. The mRNA expression levels of DII1, DII4, Jagged1 and Jagged2 were assessed by real-time q-PCR and normalized with GAPDH as described in the Methods. Each dot represents individual case and the horizontal line represents the mean.

Statistical significance was evaluated by unpaired student's t-test with Welch's correction.

with the duration of fever, length of hospital stay, the biochemical markers CRP, Glu, Alt, Ast, CK and CK$\mathrm{MB}$, and the PRISM III score (data not shown).

\section{Discussion}

HFMD is a virus-induced infectious disease, which can lead to serious consequences especially in infants and children. Several studies have shown that children with HFMD undergo significant alterations in their immune status $[3,4]$. However, the precise mechanism (s) responsible for altered immune functions in patients with HFMD has not yet been fully clarified.

In the present study, we found that children with HFMD displayed significant decreases in their peripheral $\mathrm{CD}^{+}$, $\mathrm{CD}^{+} \mathrm{CD}^{+}$and $\mathrm{CD}^{+} \mathrm{CD}^{+}$cell subsets, but had a substantial increase in their peripheral $\mathrm{CD}^{-} \mathrm{CD} 19^{+}$cell subset. Moreover, children in the HFMD with encephalitis group showed further reduction in the $\mathrm{CD}^{+}$and $\mathrm{CD}^{+} \mathrm{CD}^{+}$cell subsets and elevation in the $\mathrm{CD}^{-} \mathrm{CD} 19^{+}$cell subset compared to children in the uncomplicated HFMD group.
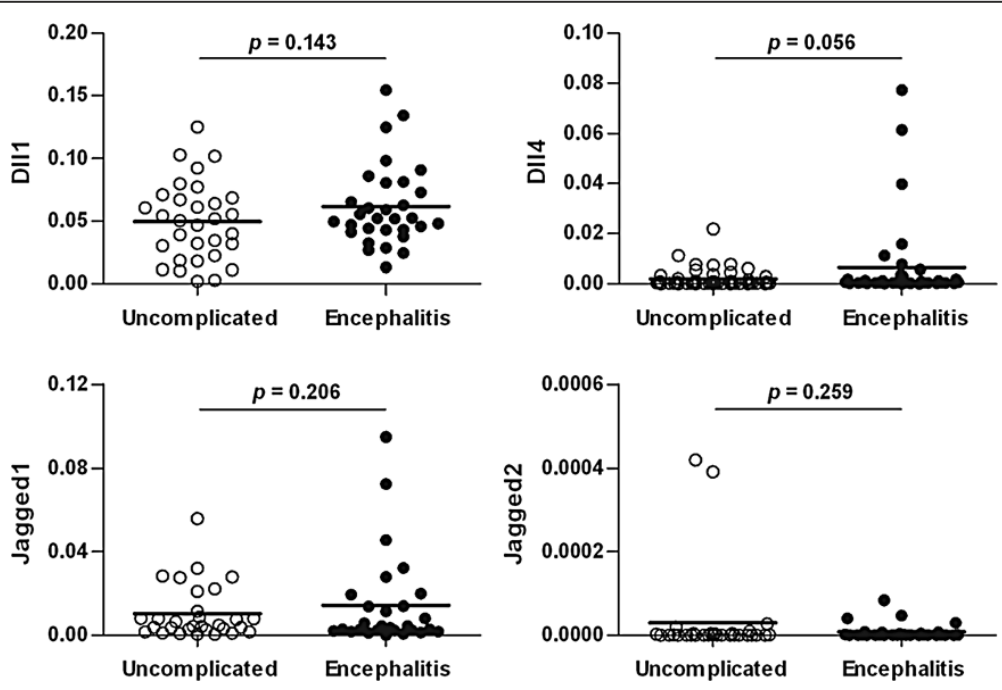

Figure 2 Comparison of the expression levels of Notch ligands DII1, DII4, Jagged1 and Jagged2 in the peripheral blood between the uncomplicated HFMD group $(\mathbf{n}=\mathbf{4 2})$ and the HFMD with encephalitis group $(\mathbf{n}=\mathbf{4 0})$. The mRNA expression levels of D\|1, D\|4, Jagged1 and Jagged2 were assessed by real-time q-PCR and normalized with GAPDH as described in the Methods. Each dot represents individual case and the horizontal line represents the mean. Statistical significance was evaluated by unpaired student's t-test with Welch's correction. 

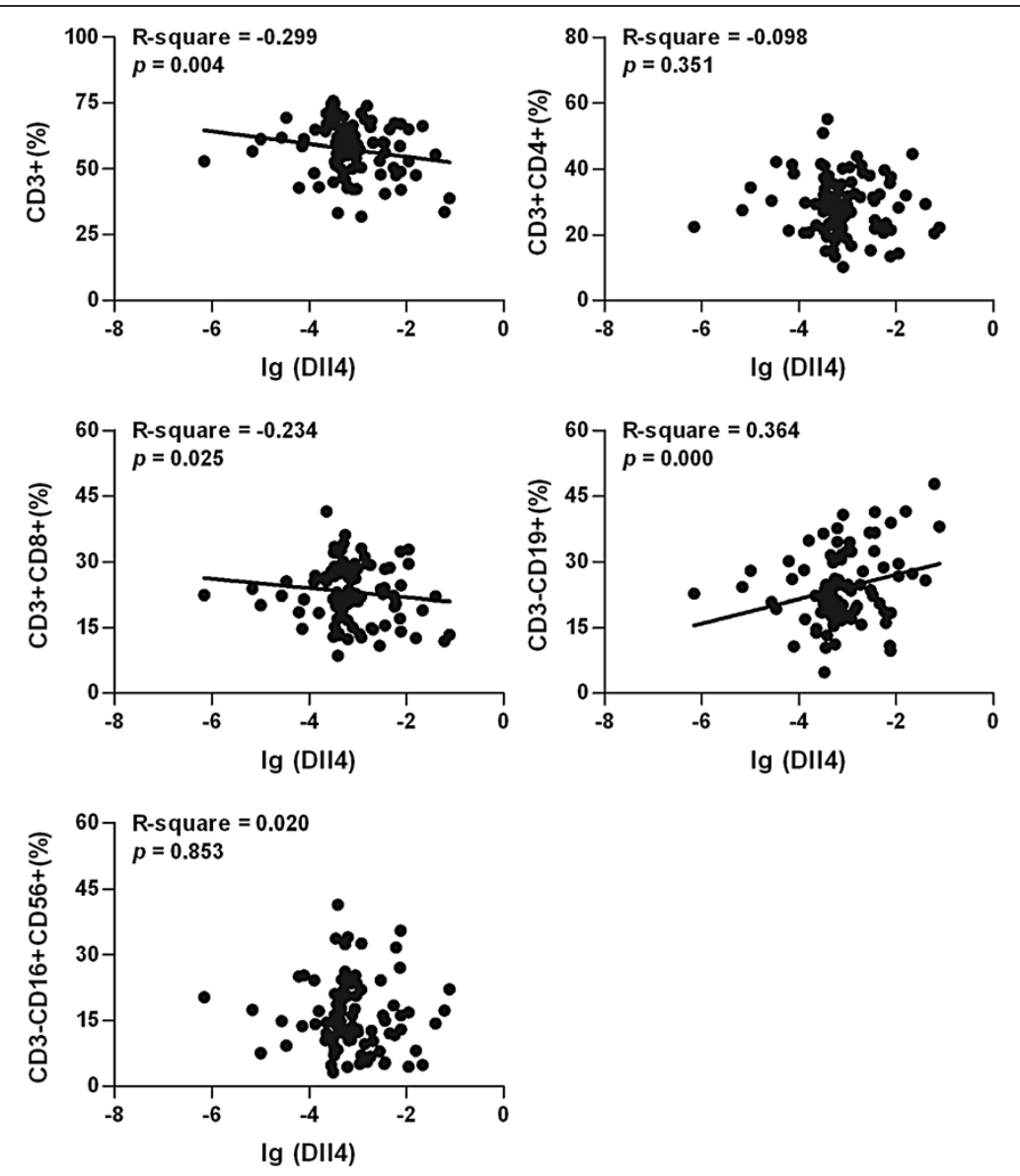

Figure 3 Correlation between the Dll4 expression levels and the $\mathrm{CD}^{+}, \mathrm{CD}^{+} \mathrm{CD}^{+}, \mathrm{CD}^{+} \mathrm{CD}^{+}, \mathrm{CD}^{-} \mathrm{CD} 19^{+}$, or $\mathrm{CD} 3^{-} \mathrm{CD} 16+\mathrm{CD}^{+} 6^{+}$cell subsets in HFMD patients $(\mathbf{n}=\mathbf{8 2}$ ). D\|l4 mRNA expression and lymphocyte subsets were assessed by real-time $q-P C R$ and FACScan analysis respectively, as described in the Methods. Each dot represents individual case and each line indicates the best-fit line. $R^{2}$ values were calculated by Spearman rank correlation coefficient test.

These results are consistent with previously reported findings in the mainland of China and Taiwan [3,4]. We also found significant increases in the expression levels of Notch ligands Dll1 and Dll4 in the peripheral blood of children with HFMD, suggesting that Notch signaling might be initiated and activated during HFMD via the engagement of upregulated Notch ligand Dll1 or Dll4 with
Notch receptors, which subsequently affects the differentiation and development of $\mathrm{T}$ and $\mathrm{B}$ lymphocytes.

It is unclear whether the Notch signaling is associated with changes in the immune status observed in children with HFMD. Previous studies have shown that the Notch signaling pathway possesses a crucial role in differentiations of a variety of immune cells [13,14]. Mukuherjee et al. [15]
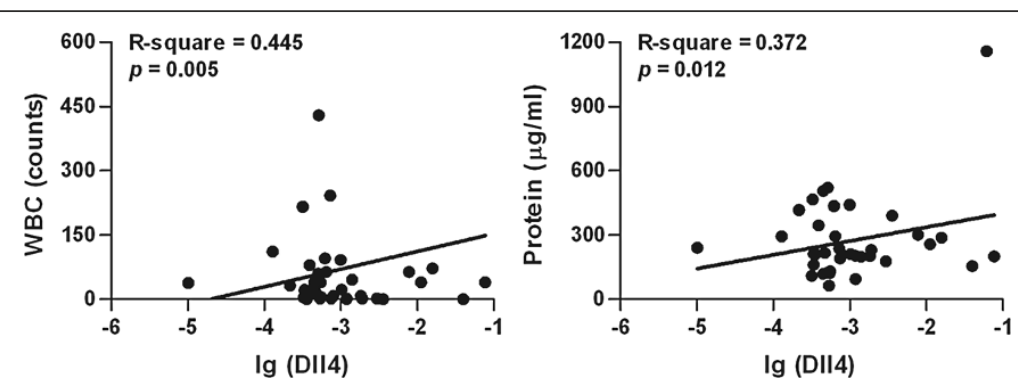

Figure 4 Association between the DII4 expression levels and CSF WBC counts or CSF protein contents in HFMD patients with encephalitis $(\mathbf{n}=\mathbf{4 0})$. DII4 mRNA expression was assessed by real-time q-PCR. CSF WBC counts and protein contents were determined as described in the Methods. Each dot represents individual case and each line indicates the best-fit line. $R^{2}$ values were calculated by Spearman rank correlation coefficient test. 
found that the Notch ligand Dll4 promoted T-cell differentiation through increased expression of IL-17 and RORy T. Schaller et al. [10] also found that Dll4 expression on bone marrow-derived dendritic cells (DCs) increased significantly after infection of mice with respiratory syncytial virus, accompanied by increased secretion of Th2 cytokines and reduced production of INF- $\gamma$. In the present study, we performed a correlation analysis of the cell counts of different lymphocyte subsets with Notch ligand expression levels in the peripheral blood of children with HFMD. Our data demonstrated that peripheral lymphocyte subsets had statistically significant correlations with the Notch ligand Dll4 expression. The Dll4 expression levels showed negative correlations with $\mathrm{CD}^{+}$and $\mathrm{CD}^{+} \mathrm{CD}^{+}$cell subsets, but a positive correlation with $\mathrm{CD}^{-} \mathrm{CD} 19^{+}$cell subset that has the $\mathrm{B}$ lymphocyte surface antigen characteristics, suggesting that the up-regulated Dll4 expression may be associated with a relatively inhibited status of $\mathrm{CD}^{+}$lymphocytes and a relatively activated status of $\mathrm{CD}^{-} \mathrm{CD} 19^{+}$lymphocytes observed in children with HFMD. It has been reported that the prognosis of sepsis correlates closely with the numbers of $\mathrm{NK}$ cells, $\mathrm{CD}^{+}, \mathrm{CD}^{+} \mathrm{CD}^{+}$and $\mathrm{CD}^{+} \mathrm{CD}^{+}$lymphocytes [16]. Therefore, it is possible that the Notch signaling pathway also affects HFMD prognosis by interfering with the number and status of these immune cells.

In the present study, we further showed that the Dll4 expression levels in the peripheral blood correlated positively with total WBC counts and total protein contents in CSF, but there were no correlations of the Dll4 expression levels with the duration of fever, length of hospital stay, the biochemical markers CRP, Glu, Alt, Ast, CK and CK-MB, and the PRISM III score. The total WBC counts and total protein contents in CSF are critical for the diagnosis of encephalitis and are also indicators for the degree of brain inflammation $[17,18]$. However, we did not observe any significant differences in Notch ligand expression such as the Dll4 level between the uncomplicated HFMD group and the HFMD with encephalitis group. Further work is needed to verify whether Dll4 can be used as a clinical indicator for determination of the severity of HFMD.

A crucial cause of death in children with severe HFMD is the neurogenic pulmonary edema. Infection with EV71 generates viremia or penetrates directly into the central nervous system where it mainly affects the brainstem, which leads to disorders of the autonomic nerve function and stimulation of sympathetic nerve system [19-22]. The over-activated sympathetic nerve system causes a massive release of catecholamines [23], resulting in systemic vasoconstriction and a shift of blood flow from the systemic circulation to the pulmonary circulation, which finally leads to the development of neurogenic pulmonary edema. It has been reported that activation of angiopoietin 2 and Dll4 can promote regeneration of the damaged dopamine neurons, thereby resulting in catecholamine such as dopamine release [24]. Children with severe HFMD may also release significant amounts of catecholamine. In the present study, we further observed substantially up-regulated Notch ligand Dll4 (or activation of Dll4) in children with HFMD. Thus, our further work will examine whether pharmacological inhibition of Dll4 could attenuate catecholamine release, thereby reducing the incidence of neurogenic pulmonary edema in children with severe HFMD.

\section{Conclusions}

Children with HFMD undergo significant changes in their immune status, and the Notch signaling pathway may play an important role in these changes. Furthermore, the Notch ligand Dll4 correlates strongly with the peripheral $\mathrm{CD}^{+}, \mathrm{CD}^{+} \mathrm{CD}^{+}$and $\mathrm{CD}^{-} \mathrm{CD}^{-} 9^{+}$lymphocyte subsets, indicating that Dll4 may participate in the pathogenesis of HFMD by interfering with the number and status of these immune cells.

\section{Abbreviations}

CoxA 16: Coxsackie A virus A16; CSF: Cerebrospinal fluid; DCs: Dendritic cells; ECD: phycoerythrin-texas red; EV71: Enterovirus 71; FITC: Fluorescein

isothiocyanate; HFMD: Hand, foot and mouth disease; NK cells: Natural killer cells; PE: Phycoerythrin; PRISM III: Pediatric risk of mortality III; q-PCR: quantitative RT-PCR; WBC: White blood cells.

\section{Competing interests}

The authors declare that they have no competing interests.

\section{Authors' contributions}

ZJB, YPL, JHW, JW conceived and designed the experiments. ZJB, YPL, JH, YJX, CYL performed the experiments. ZJB, YPL, XXK, JMT, JHW, JW analyzed the data. ZJB, YPL, JHW, JW wrote the paper. All authors read and approved the final manuscript.

\section{Acknowledgements}

This work was supported by the National Natural Science Foundation of China (Grant 81272143), the National Natural Science Foundation of Jiangsu Province (Grant BK2011310), Jiangsu Innovation Team (Grant L201141), Jiangsu Province Program of Innovative and Entrepreneurial Talents (2011-2014).

\section{Author details}

'Pediatric Intensive Care Unit, Affiliated Children's Hospital, Soochow University, Suzhou, China. ${ }^{2}$ Institute of Pediatric Research, Affiliated Children's Hospital, Soochow University, Suzhou, China. ${ }^{3}$ Department of Pediatric Surgery, Affiliated Children's Hospital, Soochow University, Suzhou, China. ${ }^{4}$ Department of the Infectious Disease, Affiliated Children's Hospital, Soochow University, Suzhou, China. ${ }^{5}$ Department of Academic Surgery, University College Cork, Cork University Hospital, Cork, Ireland.

Received: 30 August 2013 Accepted: 12 June 2014 Published: 17 June 2014

\section{References}

1. CDC. [http://www.moh.gov.cn/mohibyfkzi/s3578/201202/54106.shtml] [www.moh.gov.cn/jkj/.../26700e8a83c04205913a106545069a11.shtml]

2. Xing W, Liao Q, Viboud C, Zhang J, Sun J, Wu JT, Chang Z, Liu F, Fang VJ, Zheng Y, Cowling BJ, Varma JK, Farrar JJ, Leung GM, Yu H: Hand, foot, and mouth disease in China, 2008-12: an epidemiological study. Lancet Infect Dis 2014, 14:308-318. 
3. Fu D, Li CR, He YX, Zu Y, Cao DZ, Wang GB, Deng JK, Wang HP: Changes of immune function in patients with enterovirus 71 infection. Zhonghua $E r$ Ke Za Zhi 2009, 47:829-834

4. Wang SM, Lei HY, Huang KJ, Wu JM, Wang JR, Yu CK, Su IJ, Liu CC: Pathogenesis of enterovirus 71 brainstem encephalitis in pediatric patients: roles of cytokines and cellular immune activation in patients with pulmonary edema. J Infect Dis 2003, 188:564-570.

5. Kopan R, llagan MX: The canonical Notch signaling pathway: unfolding the activation mechanism. Cell 2009, 137:216-233.

6. Lukacs NW, Smit JJ, Schaller MA, Lindell DM: Regulation of immunity to respiratory syncytial virus by dendritic cells, toll-like receptors, and notch. Viral Immunol 2008, 21:115-122

7. Ito T, Connet JM, Kunkel SL, Matsukawa A: Notch system in the linkage of innate and adaptive immunity. J Leukoc Biol 2012, 92:59-65.

8. Andersson $E R$, Sandberg $R$, Lendahl U: Notch signaling: simplicity in design, versatility in function. Development 2011, 138:3593-3612

9. Ito T, Allen RM, Carson WF 4th, Schaller M, Cavassani KA, Hogaboam CM Lukacs NW, Matsukawa A, Kunkel SL: The critical role of Notch ligand Delta-like 1 in the pathogenesis of influenza A virus (H1N1) infection. PLoS Pathog 2011, 7:e1002341.

10. Schaller MA, Neupane R, Rudd BD, Kunkel SL, Kallal LE, Lincoln P, Lowe JB, Man Y, Lukacs NW: Notch ligand Delta-like 4 regulates disease pathogenesis during respiratory viral infections by modulating Th2 cytokines. J Exp Med 2007, 204:2925-2934.

11. WHO: A guide to clinical management and public health response for hand, foot and mouth disease (HFMD). [http://www.wpro.who.int/ publications/docs/GuidancefortheclinicalmanagementofHFMD.pdf]

12. Pollack MM, Patel KM, Ruttimann UE: PRISM III: an updated pediatric risk of mortality score. Crit Care Med 1996, 24:743-752.

13. Van de Walle I, De Smet G, De Smedt M, Vandekerckhove B, Leclercq G, Plum J, Taghon T: An early decrease in Notch activation is required for human TCR-alphabeta lineage differentiation at the expense of TCRgammadelta T cells. Blood 2009, 113:2988-2998.

14. Amsen D, Antov A, Jankovic D, Sher A, Radtke F, Souabni A, Busslinger M, McCright B, Gridley T, Flavell RA: Direct regulation of Gata 3 expression determines the $\mathrm{T}$ helper differentiation potential of Notch. Immunity 2007, 27:89-99.

15. Mukuherjee S, Schaller MA, Neupane R, Kunkel SL, Lukacs NW: Regulation of $T$ cell activation by Notch ligand, DLL4, promotes IL-17 production and Rorc activation. J Immunol 2009, 182:7381-7388.

16. Andaluz-Ojeda D, Iglesias V, Bobillo F, Almansa R, Rico L, Gandía F, Loma AM, Nieto C, Diego R, Ramos E, Nocito M, Resino S, Eiros JM, Tamayo E, de Lejarazu RO, Bermejo-Martin JF: Early natural killer cell counts in blood predict mortality in severe sepsis. Crit Care 2011, 15:R243.

17. Kim SJ, Kim JH, Kang JH, Kim DS, Kim KH, Kim KH, Kim YH, Chung JY, Bin JH, Jung Da E, Kim JH, Kim HM, Cheon DS, Kang BH, Seo SY: Enteroviruses Complications Working Group: Risk factors for neurologic complications of hand, foot and mouth disease in the Republic of Korea, 2009. J Korean Med Sci 2013, 28:120-127.

18. Cho HK, Lee NY, Lee H, Kim HS, Seo JW, Hong YM, Lee SJ, Lee SW, Cheon DS, Hong JY, Kang BH, Kim JH, Kim KH: Enterovirus 71-associated hand, foot and mouth diseases with neurologic symptoms, a university hospital experience in Korea, 2009. Korean J Pediatr 2010, 53:639-643.

19. Wang SM, Liu CC, Tseng HW, Wang JR, Huang CC, Chen YJ, Yang YJ, Lin SJ, Yeh TF: Clinical spectrum of enterovirus 71 infection in children in southern Taiwan, with an emphasis on neurological complications. Clin Infect Dis 1999, 29:184-190.

20. Kao SJ, Yang FL, Hsu YH, Chen HI: Mechanism of fulminant pulmonary edema caused by enterovirus 71. Clin Infect Dis 2004, 38:1784-1788.

21. Zeng $H$, Wen F, Gan Y, Huang W: MRI and associated clinical characteristics of EV71-induced brainstem encephalitis in children with hand-foot-mouth disease. Neuroradiology 2012, 54:623-630.

22. Zheng $X Q$, Chen $X Q$, Gao Y, Fu M, Chen YP, Xu DP, Lin A, Yan WH: Elevation of human leukocyte antigen- $G$ expression is associated with the severe encephalitis associated with neurogenic pulmonary edema caused by enterovirus 71. Clin Exp Med 2013. April 21. [Epub ahead of print]
23. Inamasu J, Sugimoto K, Yamada $Y$, Ganaha T, Ito K, Watabe T, Hayashi T, Kato $Y$, Ozaki $Y$, Hirose $Y$ : The role of catecholamines in the pathogenesis of neurogenic pulmonary edema associated with subarachnoid hemorrhage. Acta Neurochir 2012, 154:2179-2184.

24. Androutsellis-Theotokis A, Rueger MA, Park DM, Mkhikian H, Korb E, Poser SW, Walbridge S, Munasinghe J, Koretsky AP, Lonser RR, McKay RD: Targeting neural precursors in the adult brain rescues injured dopamine neurons. Proc Natl Acad Sci USA 2009, 106:13570-13575.

doi:10.1186/1471-2334-14-337

Cite this article as: Bai et al:: The significance of Notch ligand expression in the peripheral blood of children with hand, foot and mouth disease (HFMD). BMC Infectious Diseases 2014 14:337.

\section{Submit your next manuscript to BioMed Central and take full advantage of:}

- Convenient online submission

- Thorough peer review

- No space constraints or color figure charges

- Immediate publication on acceptance

- Inclusion in PubMed, CAS, Scopus and Google Scholar

- Research which is freely available for redistribution

Submit your manuscript at www.biomedcentral.com/submit
C) BioMed Central 